\title{
뉴질랜드 대외원조 개관 ${ }^{1)}$
}

\section{I . 뉴질랜드 원조 개요}

\section{1. 뉴질랜드의 원조 목표 및 방향}

1) 정책 기조

ㅁ 개도국의 빈곤해소를 궁극적 목표로 "빈곤 없는 안전하고 정의로운 세계 지향 (Towards a safe and just world free of poverty) 및 5개년 전략 (the Five Year Strategy/2004. 5 2009. 10)을 주요 정책기조로 삼고 있음.

\section{2) 주요 정책 방향}

ㅁ 개도국의 빈곤해소

ㅁ 신정책체제(New Policy Framework) 및 태평양 지역 전략보고서(Pacific Regional Strategy Papers)의 틀 안에서 국제개발목표(International Development Targets)와 MDGs의 통합 노력
ㅁ국별 빈곤분석 및 프로그램 전략에 기초한 양자간 원조 실시

ㅁ태평양 지역의 개도국 중점 지원 막ㄱ 개도국의 특이한 상황을 고려, 기초교육 수요 충족을 위한 효과적인 국가별 교육전략 개발 민ㄴ권, 성평등 및 환경문제의 주류화 ㅁㄴ질랜드 $\mathrm{ODA}$ 사업 효과 측정을 위한 감시 및 평 가시스템의 구축 등

\section{2. 개발원조에 대한 국민적 지지 현황}

ㅁ2004년 NZAID(뉴질랜드 국제개발청)가 실시한 여론조사에 따르면 뉴질랜드 국민의 $76 \%$ 가 대 개 도국 원조를 지지하고 있으며 동 지지자 중 $61 \%$ 가 GNI 대비 $0.7 \%$ 수준으로 원조예산 증액을 하는데 찬성하였음. 그러나 $\mathrm{NZAID}$ 의 활동 및 실적에 대 한 국민 인지도는 $30 \%$ 정도로 낮은 수준임. 또한 
원조가 테러 및 전염병의 확산을 억제하는 기능을 해야 한다는 인식이 보편화되어 있고, 원조우선 대 상국으로는 태평양지역 국가를 선호하는 것으로 나타났음.

ㅁ원조를 반대하는 국민들은 그 이유로 국내 빈곤층 에 대한 우선 지원 및 개도국의 부패로 인한 예산 낭비 등을 들고 있음. 응답자들은 전반적으로 원조 사업을 지지하였으나 정부원조 프로그램의 효과 성에 대해서는 $60 \%$ 가 의구심을 나타냄.

\section{II. 뉴질랜드 원조 현황}

\section{1. 최근 뉴질랜드의 ODA 지원 현황}

ㅁ 2003년도 ODA 규모 : US\$165백만(ODA/GNI 비율 : $0.23 \%)$

- 2003년 ODA 총액기준으로 DAC 22개 회원국 중 최하위이며, $\mathrm{ODA} / \mathrm{GNI}$ 비율 기준으로는 16 위임(DAC 회원국 평균은 $0.25 \%)$

- 2003년 원조액은 전년 대비 43백만불(35\%) 증 가하였으나 장기적 예산규모 확대 추세는 보이

〈뉴질랜드 연도별 ODA 및 ODA/GNI 추이〉

\begin{tabular}{c|c|c}
\multicolumn{1}{c|}{} & (단위:US\$ 백만) \\
\hline 구분 & ODA & ODA/GNI \\
\hline 1999년 & 134 & 0.27 \\
2000년 & 113 & 0.25 \\
2001년 & 112 & 0.25 \\
2002년 & 122 & 0.22 \\
2003년 & 165 & 0.23 \\
\hline
\end{tabular}

※자료:OECD, The DAC Journal : Development Co-operation Report 2004, Table 4

지 않고 있으며 왕성한 경제성장률에 비해 ODA 증가율은 저조한 편임.

- 뉴질랜드 정부의 공식적 원조규모 확대 목표는 유엔 권고수준인 $\mathrm{ODA} / \mathrm{GNI}$ 비율 $0.7 \%$ 이나 현 재 구체적 중장기 계획은 부재하며 동 목표달성 을 위한 정부의 의지도 미약한 실정임.

\section{2003년 뉴질랜드 ODA 세부내역}

1) ODA 규모 : US\$165백만

- 양자간 ODA 규모 : US\$129백만(78.18\%)

- 다자간 ODA 규모 : US\$36백만(21.82\%)

ㅁ뉴질랜드는 지정학적 특성상 태평양 지역의 번영 과 안정을 위한 평화구축 및 분쟁예방을 위해 취약 국가 지원에 중점을 두고 있으며, 이는 뉴질랜드가 지원한 과거의 주요 수원국이 남태평양 지역에 집 중되어 있다는 점에서 잘 드러나고 있음.

2002 2003년 이라크에 대한 원조와 최근 남아시

〈2002 2003년도 상위 10대 수원국 지원 규모 및 점유율〉

(단위:US\$ 백만)

\begin{tabular}{|c|c|c|c|}
\hline 순위 & 국명 & $\begin{array}{c}\text { 지원규모 } \\
\text { (2002 03년 평균) }\end{array}$ & $\begin{array}{l}\text { 총 ODA 대비 점유율 } \\
\text { (2002 03 평균) }\end{array}$ \\
\hline 1 & 파푸아뉴기니 & 6.9 & $4.8 \%$ \\
\hline 2 & 니우 & 5.9 & $4.1 \%$ \\
\hline 3 & 이라크 & 5.8 & $4.0 \%$ \\
\hline 4 & 토켈라우 & 5.3 & $3.7 \%$ \\
\hline 5 & 솔로몬 군도 & 4.8 & $3.3 \%$ \\
\hline 6 & 사모아 & 4.8 & $3.3 \%$ \\
\hline 7 & 인도네시아 & 4.6 & $3.2 \%$ \\
\hline 8 & 바누아투 & 4.0 & $2.8 \%$ \\
\hline 9 & 통가 & 3.7 & $2.6 \%$ \\
\hline 10 & 쿡아일랜드 & 3.0 & $2.1 \%$ \\
\hline \multicolumn{2}{|r|}{ 합계 } & 48.8 & $33.9 \%$ \\
\hline \multicolumn{2}{|c|}{ ODA 총규모 } & 144 & \\
\hline
\end{tabular}


〈상위 10 대 수원국 추이 및 총 ODA 대비 양자간 원조 비율〉

\begin{tabular}{c|c|c|c|c|c|c}
\hline 순위 & 국명 (1982-83) & $\%$ & 국명 (1992-93) & $\%$ & 국명 $(2002-03)$ & \% \\
\hline 1 & 쿡아일랜드 & 12.6 & 쿡아일랜드 & 7.6 & 파푸아뉴기니 & 4.8 \\
2 & 니우 & 7.3 & 사모아 & 7.0 & 니우 & 4.1 \\
3 & 인도네시아 & 7.1 & 피지 & 6.8 & 이라크 & 4.0 \\
4 & 사모아 & 5.6 & 통가 & 4.1 & 토켈라우 & 3.7 \\
5 & 피지 & 4.2 & 니우 & 4.0 & 솔로몬 군도 & 3.3 \\
6 & 통가 & 2.8 & 파푸아뉴기니 & 3.4 & 사모아 & 3.3 \\
7 & 파푸아뉴기니 & 2.8 & 토켈라우 & 3.3 & 인도네시아 & 3.2 \\
8 & 토켈라우 & 1.8 & 인도네시아 & 2.8 & 바누아투 & 2.8 \\
9 & 필리핀 & 1.6 & 솔로몬 군도 & 2.6 & 통가 & 2.6 \\
\hline 10 & 태국 & 1.5 & 바누아투 & 1.5 & 쿡아일랜드 & 2.1 \\
\hline
\end{tabular}

※ 자료: OECD, The DAC Journal : Development Co-operation Report 2004, Table 32

아 쓰나미 긴급재해구호를 위한 예산 배정으로 총 $\mathrm{ODA}$ 중 인도적 원조 자금의 규모가 증가하고 있 는 추세임.

\section{2) 유상/무상원조 규모}

-무상원조(Grants and grant like contribution) : US\$ 165백만(100\%)

- 유상원조(Development lending and capital) :

US\$ - (0\%)

※ 뉴질랜드의 모든 ODA 예산은 무상원조 형태로 집행되고 있음.

\section{3) 지역별 지원 현황}

대평양 및 동남아시아 지역 19 개 최빈국, 기타 저 소득국 및 중저소득국 등에 집중되어 있음. 오세아 니아 지역에 대한 지원은 1999 년 이후 감소추세에 있으며 이라크 원조규모의 증대로 최근 중동지역 에 대한 비중이 확대되었음.
ㅁㅜㅜㅇㅛ 수원대상국이 주로 태평양 및 아시아 지역의 저개발국들이나 전체 수원국 수는 늘어나고 있는 추세임. 상위 20 개 수원국에 대한 원조 비중이 1992 3년 96\%에서 1997 8년 86\%, 2002 03년 $79 \%$ 로 줄어들고 있으며 수원국 수는 각 66 개국, 92 개국 및 100 개국으로 지속적인 증가 양상을 보 이고 있음.

〈지역별 지원현황(양자간 원조 비율)〉

\begin{tabular}{c|c|c|c}
\hline \hline 지 역 & $1982 \sim 83$ & $1992 \sim 93$ & 2002 03 \\
\hline 유럽 & - & 0.2 & 0.0 \\
사하라이북 아프리카 & 0.0 & 0.0 & 0.0 \\
사하라이남 아프리카 & 0.4 & 2.1 & 9.1 \\
북중미 & 0.1 & 0.4 & 0.7 \\
남미 & 0.1 & 0.4 & 1.7 \\
중동 & 0.0 & 0.0 & 6.7 \\
서남아 및 중앙아시아 & 1.5 & 0.9 & 6.0 \\
극동아시아 & 14.3 & 12.1 & 18.5 \\
오세아니아 & 83.6 & 83.8 & 57.3 \\
\hline 합계 & 100 & 100 & 100 \\
\hline
\end{tabular}

※자료:OECD, The DAC Journal : Development Co-operation Report 2004, Table 32 


\section{4) 소득그룹별 지원 현황}

〈소득그룹별 지원현황(양자간 원조 비율)〉

(단위:\%)

\begin{tabular}{c|c|c|c}
\hline 지 역 & $1982 \sim 83$ & $1992 \sim 93$ & 2002 03 \\
\hline \hline 최빈개도국(LDCs) & 17.0 & 29.4 & 37.4 \\
기타저소득국(Other LICs) & 18.3 & 13.4 & 19.6 \\
중저소득국(LMICs) & 41.0 & 41.2 & 37.2 \\
고중소득국(UMICs) & 23.4 & 15.5 & 5.7 \\
고소득국(HICs) & - & - & - \\
MADCT') & 0.4 & 0.5 & - \\
\hline 합계 & 100.0 & 100.0 & 100.0 \\
\hline
\end{tabular}

주1) MADCT: More Advanced Developing Countries and Territories(동 국가에 대한 지원 은 OA(Official Aid)로 분류

※ 자료: OECD, The DAC Journal : Development Co-operation Report 2004, Table 32

\section{5) 2003년도 분야별 지원 현황}

〈2003년도 분야별 지원실적〉

(단위:\%)

\begin{tabular}{|c|c|c|}
\hline \multicolumn{2}{|c|}{ 분야 } & 2003년도 \\
\hline \multirow{6}{*}{$\begin{array}{l}\text { 사회 및 행정 인프라1) } \\
\text { (Social and administrative } \\
\text { infrastructure) }\end{array}$} & 교육(기초교육) & 23.8(2.7) \\
\hline & 보건(기초보건) & 5.6(4.2) \\
\hline & 인구 & 0.6 \\
\hline & 식수 및 위생 & 1.0 \\
\hline & 정부 및 시민사회 & 8.6 \\
\hline & 기타 사회인프라/서비스 & 7.7 \\
\hline \multicolumn{2}{|c|}{ 소계 } & 47.4 \\
\hline \multirow{3}{*}{$\begin{array}{l}\text { 경제인프랄) } \\
\text { (Economic infrastructure) }\end{array}$} & 교통 및 통신 & 1.1 \\
\hline & 에너지 & 0.6 \\
\hline & 기타 & 1.9 \\
\hline \multicolumn{2}{|c|}{ 소 계 } & 3.6 \\
\hline \multirow{3}{*}{ 생산(Production) } & 농업 & 2.6 \\
\hline & 제조업, 광업 및 건축 & 0.4 \\
\hline & 무역 및 관광 & 1.2 \\
\hline \multicolumn{2}{|c|}{ 소 계 } & 4.2 \\
\hline \multicolumn{2}{|l|}{ 다부문(Multisector) } & 5.1 \\
\hline \multicolumn{2}{|c|}{ 프로그램원조(Programme assistance) } & 8.7 \\
\hline \multicolumn{2}{|c|}{ 부채탕감(Action relating to debt) ${ }^{3)}$} & - \\
\hline \multicolumn{2}{|l|}{ 긴급원조(Emergency aid) } & 13.2 \\
\hline \multicolumn{2}{|c|}{ 행정경비(Administrative expenses) } & 8.1 \\
\hline \multicolumn{2}{|l|}{ 기타(Unspecified) } & 9.8 \\
\hline \multicolumn{2}{|l|}{ 합 계 } & 100.0 \\
\hline \multicolumn{3}{|l|}{$\begin{array}{l}\text { 주1) 학생 및 연수생 포함 } \\
\text { 2) 인구 및 생식보건 }\end{array}$} \\
\hline
\end{tabular}

ㅁ빈곤감소를 위해 사회 및 행정 인프라 부문에 $\mathrm{ODA}$ 를 집중하고 있으며 특히, 기초교육 분야에 많은 예산을 할당하였음.

\section{〈분야별 지원실적 추이〉}

(단위:\%)

\begin{tabular}{c|c|c}
\hline 지원년도 & 1982 83 & 2002 03 \\
\hline 사회/행정 인프라 & 22.4 & 47.8 \\
경제 인프라 & 27.3 & 4.0 \\
농업 & 16.8 & 2.6 \\
산업/기타생산 & 3.7 & 1.8 \\
물자/프로그램지원 & 24.2 & 7.4 \\
긴급지원 & 2.1 & 12.7 \\
기타 & 3.5 & 23.7 \\
\hline
\end{tabular}

※자료: OECD, The DAC Journal : Development Co-operation Report 2004, Table 18

\section{III. 주요 의제별 정책}

\section{1. 빈곤감소}

1) NZAID(뉴질랜드 국제개발청)의 설립과 빈곤문 제의 중점화

2002년 NZAID가 설립되면서 뉴질랜드 ODA 사 업의 최대 핵심과제로 빈곤감소가 부각되었고 'Towards a safe and just world free from poverty' 및 기타 정책 보고서와 전략 등에서 빈 곤해소를 위한 접근방식을 명시함.

ㅁ 빈곤감소를 위해 $\mathrm{NZADD}$ 는 시민사회, 지역사회 등 과 함께 국가 · 지역 · 국제사회에 대한 정책의 틀을 확립하고 다양한 직·간접 원조를 수행하고 있음. ㅁ이에 개도국의 교육, 보건, 생계유지 등의 기본적 욕구를 충족시키고 사회적 · 문화적 · 환경적 · 경 제적 여건들의 개선을 위해 노력하고 있음. 


\section{2) 경제성장과 지속가능한 생계의 촉진}

$\square$ 태평양 연안 개도국에 대한 경제발전을 주요 과제 로 삼고 있는 뉴질랜드는 건실하고 역동적인 민간 부문의 장려가 수원국 국민의 삶의 질을 높이고 지속적인 빈곤감소를 위해 필수조건임을 인식하 고 있음.

민ㄴ곤감소를 위해 거시 및 미시적 수준을 포괄하는 정책을 개발하고 있으며 동 정책에는 경제성장, 민 간부문강화, 식량안보 및 무역 등의 주요 이슈들이 포함됨.

\section{3) MDGs 달성 노력}

ㅁ뉴질랜드의 IDTs(International Development Targets)와 MDGs 달성을 위한 노력은 정책기조인 'Towards a safe and just world free of poverty' 에 융해되어 있으며 수원국과 국제사회와 의 협력을 위한 전략과 정책에도 잘 반영되어 있음. ㅁ분야별 원조를 하는 NZAID는 원조 목표설정과 효 과분석에 $\mathrm{MDGs}$ 를 활용도를 높이고 있으나 MDGs 달성을 위한 $\mathrm{ODA}$ 의 규모 증가의 국제적 움직임에는 미온적 태도를 보이고 있음.

\section{2. 교육부문 지원}

ㅁ교육분야는 뉴질랜드의 양자간 $\mathrm{ODA}$ 의 3 분의 1 을 차지하고 있으며 이는 단일 분야로서는 최대 규모 임. 그동안 장학금 지원을 통한 고등교육 지원에 집중해 왔으나 2000년 동료 심사에서의 권고사항 을 적극 수용, 초·중등 기초교육에 대한 지원을 강화하고 있음.

\section{1) 수원국의 교육제도 개선 지원}

ㅁ NZAID의 교육정책 방향은 기초교육 및 고등교육 의 균형있는 지원이며 특히 교육에서의 성평등에 주안점을 두고 있음.

ㅁㅇㄹ래의 4 가지 원칙을 교육분야에 대한 우선지원의 근거로 삼고 있음.

(1) 교육은 기본적 인간의 권리임.

(2) 교육은 그 자체로서 목적임.

(3) 국제사회는 인권의 보장과 만인을 위한 교육' 달성에 공동의 노력을 경주하고 있음.

(4) 교육은 빈곤근절, 효과적 거버넌스와 리더십 그 리고 기타 개발목표를 달성하는데 기여함.

ㅁㅊ근의 교육분야 지원에 있어서 가장 두드러진 변 화는 Sector wide approaches(SWAp)의 틀 속에 서 광범위한 교육재정 지원을 하고 있다는 점임. 새로운 교육정책에서는 "교육분야 육성을 위한 전 략은 있으나 재정적 자원이 부족한 수원국가에 대 해서 재정지원, 기술지원, 장학금지원 및 연수를 통한 직접적 원조를 실시한다” 고 명시하고 있음.

\section{2) 효과적인 장학금 제도 개발}

ㅁㅏㅏㅇ학금 지원은 NZAID 교육부문 전체 예산의 $80 \%$ 를 차지하며 이는 지난 20 년간 양자간 $\mathrm{ODA}$ 의 $30 \%$ 에 달함.

ㅁ장학금 지원 규모 대비 효과에 대해 2001년 장관 심 사에서 아래의 비판과 권고사항들이 제기된 바 있음.

(1) 장학금 지원은 국가 프로그램 전략, 노동시장 및 인적자원개발수요 등과 효과적으로 통합하 여 시행되어야 함. 
(2) 뉴질랜드 자국 초청 교육보다는 수원국 내 혹은 지역내 연수프로그램실시 및 장학금 지원이 비 용대비 더 효과적이고 효율적임.

(3) 거래비용절감 및 효과 증대를 위해 절차의 간소 화(Simplification of procedures), 수원국과의 조화(Harmonisation) 및 수원국 정부의 노력 과의 일치(Aligment)가 중요함.

ㅁㅊ근까지 7 개의 장학프로그램 및 시상프로그램이 있었으나 3 개는 폐쇄되었음. 이는 성과의 부진 및 목표한 개발 결과와 부합되지 않았기 때문임. 기 존의 다양한 프로그램을 뉴질랜드 개발장학제도 및 뉴질랜드 지역개발장학제도로 통폐합하려고 하고 있음.

\section{3. 취약국가 지원}

ㅁ평화와 안보는 뉴질랜드가 지원하고 있는 수원국 의 발전의 기반이 되나 태평양 연안 다수의 국가 들에서 분쟁과 불안의 양상이 지속적으로 나타나 고 있음.

ㅁㅍ푸아뉴기니의 내전, 솔로몬 군도에서의 정부붕 괴, 피지의 쿠데타 및 바누아투의 증가되는 정치적 불안정 징후 등이 그 예임.

ㅁ NZAID는 취약국가의 분쟁예방 및 평화재건을 위 해서 다음의 분야에 중점을 두고 있음.

- 거버넌스 지원과 인권존중, 성평등 이슈 해결, 사회 각 계층의 참여, 기초 사회 서비스의 개선, 경재개발 촉진 등

미역의 분쟁 예방 역량 강화와 중재 및 조정을 위 해 리더십 강화, 여성 존중, 청소년 교육,
$\mathrm{HIV} / \mathrm{AIDS}$ 예방, 지역사회 정보 제공, 법치의 강화 등을 지원하고 있음.

\section{IV. 원조 기관, 인력 및 관리 체계}

1. 원조 실시 체계

1) NZAID(New Zealand Agency for International Development)의 창설

DAC(Development Assistance Committee)는 2000년 동료심사에서 당시 외교통상부(MFAT: Ministry of Foreign Affairs and Trade)가 총괄 하고 있던 뉴질랜드 ODA 정책의 두 가지 문제점 을 지적함.

(1)지나치게 많은 소규모 프로젝트와 전략적 집중 의 부재

(2)외교통상부의 단기 순환 보직에 따른 원조 전문 가 육성의 어려움.

이에 정부는 2001년 빈곤감소에 초점을 두고 $\mathrm{ODA}$ 프로그램 전반을 재검토하게 됨.

ㅁ 이러한 과정을 거쳐 2002년 외교통상부 산하 준독립 기관으로 $\mathrm{NZADD}$ (뉴질랜드 국제개발청)이 창설됨.

ㅁ외교정책 전반은 뉴질랜드 외교통상부가 담당하 나 $\mathrm{ODA}$ 관련 사항들은 외교통상부 차관이 직접적 책임을 짐.

ㅁ 개발협력 관련 예산은 'Vote ODA' 라는 항목으로 별도 분리되어 있는데 이는 뉴질랜드 총 $\mathrm{ODA}$ 의 $90 \%$ 를 차지하며 NZAID가 관리함.

ㅁ NZAID는 단순한 원조 집행기관 이상의 역할을 하 
고 있음. 준독립기관으로서 ODA 관련 정책 및 운 영 사항에 대해 장관회의에 직접 보고서를 제출하 며 외교통상부의 견해와 다른 정책을 독립적으로 시행할 수 있음.

ㅁㄱㄱㄱ회의 감독은 연간 예산 승인 절차시 외교통상부 를 통해서만 가능하며 개발정책 입안에 정도에만 관여하는 등 NZAID에 대한 제도적 개입의 여지는 제한적임.

\section{뉴질랜드 국제개발청(NZAID)의 창설과} 뉴질랜드 ODA 정책의 변화

- NZAID의 창설로 전문성과 풍부한 경험을 가지고 개발정책 및 관련 정책에 심대한 영향을 미칠 수 있는 개발전문인력으로 구성된 전담 기관을 가지 게 됨.

- 빈곤 근절(Poverty Elimination)이 NZAID의 중심 목표로 설정되어 우선순위 선택, 원조방법 선정, 원 칙설정 등의 근간이 됨.

- 새로운 일련의 정책, 원조체계, 결과중심의 계획 및 실행 문화 등을 창조함.

- 수원국의 정책 및 행정기관이 취약하더라도 최신 프로그램의 전수, 우선순위를 바탕으로 한 원조 및 적절한 의사결정절차를 수행할 능력을 가지게 됨.

- 고등교육보다 기초교육에 강조를 둠으로써 바람직 한 교육프로그램의 변화를 이룸.

- 결과 중심주의로의 원조정책 전환. 이러한 관행은 수원국 및 국제기관과 보다 대규모의(Bigger), 보다 소수와의(Fewer), 보다 깊은(Deeper), 보다 장기간 의(Longer) 관계를 형성케 함.

\section{2) NZAID와 MFAT(외교통상부)의 관계}

NZAID 청장은 외교통상부 장관이 임명하나 그 외 임직원의 인사권은 청장에게 있음. NZAID는 외교 통상부 내에 위치해 있으며 두 기관 간의 관계를 규정하는 문서는 Letter of Expectation과 Relationship document임. NZAID 청장은 외교 통상부 Senior Management Group의 임원으로 매주 외교통상부장관과 회의를 하며 두 기관의 실 무자들도 정규 및 비정규 모임을 가짐.

\section{3) NGO와 밀접한 협력체제 구축}

NZAID는 $\mathrm{NGO}$ 의 개발 관련 전문성과 경험을 인 정하여 친밀한 관계를 유지하고 있음. 다양한 채널 을 통해 $\mathrm{NGO}$ 와 개발정책 관련 협의를 하고 있으 며 이러한 협력체제는 양자 모두에게 유익한 것으 로 인식되고 있음.

ㅁㅗㅗㅇ $\mathrm{ODA}$ 의 약 $14 \%$ 가 $\mathrm{NGO}$ 에 지원되고 있으나 $\mathrm{NGO}$ 들은 전적으로 정부지원에 의지하고 있지는 않음. 대표 NGO 협의체인 $\mathrm{CID}$ 의 연례보고서에 따르면 총 NGO 예산 중 $68 \%$ 는 공공모금을 통한 것이며 정부 지원분은 $27 \%$ 에 지나지 않음. NGO 의 기금마련의 창구가 다양하므로 투명성과 일관 성이 주요 이슈로 고려되고 있음. 아울러 NZAID 와 $\mathrm{NGO}$ 간 수원국 선정 및 활동과 전략에 관한 조 정을 위해 상호 협의가 중요시되고 있음.

\section{2. 조직 운영 및 인적 관리}

1) 경영의 유연성

망ㅊㅊㅗ 외교부 담당이었던 원조 사업을 NZAID에 이 
관하여 임직원의 인사권 및 임금 결정권을 청장에 게 위임하고 독립된 예산을 배정함으로써 비독립 적인 원조전담기관 운영을 하고 있는 타 국가들보 다 효율적인 원조가 가능케 됨.

ㅁ 직원의 $70 \%$ 를 신규 채용하고 분명한 전략적 집중 과 바람직한 조직문화를 창출하여 원조사업 관련 인력의 질적 향상을 이룩함. NGO, 학계, 민간 및 타 원조기관(영국국제개발부/DFID, 호주국제개발청 /AusAID, 캐나다국제개발청/CIDA)의 인력을 고용 하여 다양하고 유연한 인력 Pool을 구성하고 있음.

\section{2) 왕성한 학습 문화}

ㅁ NZAID 설립 당시 주요 현안 중 하나는 정책개발 및 프로그램 수행과 함께 신입직원들을 조직에 통 합하는 것이었음.

ㅁ이에 대안으로 신입직원에 대한 학습 권장과 경력 개발을 위한 오리엔테이션 훈련에 집중적 투자를 실시함.

口 NZAID의 효과적 기능을 위해 다음과 같은 가치가 규정되어 실제 경영상 관행이 되었음.

- "참여적인 의사결정과 평등한 파트너십을 통해 구축된 결과중심주의에 주안점을 두고, 개방적 이고 신속히 반응하며 팀에 기초한 운영을 도 모 한다."

ㅁ직원의 경력개발과 동기부여를 위해 학습과 개발 기회를 최대화할 수 있는 직무 고안이 이루어짐.

\section{3) 제한적 해외 현장 경험}

ㅁ현재 해외사무소 파견 직원은 5 명(피지, 인도네시
〈NZAID 해외 인력 현황〉

\begin{tabular}{c|c|c}
\hline 구분 & $\begin{array}{c}\text { 정규직 환산인원 } \\
\text { (실제인원x노동비율) }\end{array}$ & $\begin{array}{c}\text { 실제 인원 } \\
\text { (노동비율) }\end{array}$ \\
\hline NZAID & 5.00 & $5(100 \%)$ \\
MFAT & 13.13 & $88(14.9 \%)$ \\
현지고용전문인력 & 19.69 & $33(59.7 \%)$ \\
현지고용인력(기타) & 20.94 & $137(15.3 \%)$ \\
총계 & 58.76 & 263 \\
\hline
\end{tabular}

아, 사모아, 솔로몬군도 및 태국)이며 5 명의 추가 인원이 파견될 예정임(피지, 파푸아뉴기니, 통가, 바누아투, 베트남 등). 원칙적으로는 Wellington 의 본부 인력이 원조사업을 수행하나 상기와 같이 일부 수원국에서는 사무소의 책임과 권한을 확대 하여 개발프로그램 운영계획을 세우고 있음.

ㅁ신규직원에게 더 많은 해외사무소 경험을 통해 전문성과 직업적 성장 기회를 제공하는 것이 주 요 과제임.

ㅁㄴㅈㅣㅣㄹ랜드의 비교적 작은 $\mathrm{ODA}$ 규모를 고려할 때 많은 수의 직원을 해외사무소에 배치하는 것은 합 리적 선택은 아니나, 적절한 전문성을 갖추지 못한 소수의 인력이 본부에만 집중되어 있는 것은 원조 의 효과를 감소시킬 수 있음. NZAID는 이러한 문 제를 Interesting team approach를 통해 극복하 려 하고 있음.

※ Interesting team approach : 본부의 국장, 담 당 부장, 외교통상부 대표 및 현지 파견 조정관 이 정기 회의를 통해 현지 현황파악 및 관련 현 안에 대한 의사결정을 내리는 제도

\section{3. 결과 중심주의 : 평가 및 기타 책임 설정 1)기관 수행 평가}


ㅁ 결과 중심주의 평가 및 경영시스템은 뉴질랜드 관 료문화에 깊이 뿌리박혀 있으며 이는 전략목표 설 정 및 실적보고와 밀접히 연관되어 있음.

ㅁ NZAID는 5개년 전략 계획을 수립하여 동 기관이 추구해야 할 목표 설정, 우선순위 선정 및 핵심전 략 수립의 근간으로 삼고 있음.

ㅁ외교통상부는 국회에 대한 예산보고시, NZAID 의 연례보고서를 포함하고 있으며 NZAID는 자 체보고서를 별도로 대중에게 공개하고 있음. 감 사원의 재무감사를 받으며 특별 회계감사가 시행 될 수도 있음.

\section{2) 자체평가의 강조}

ㅁ 2001년 내각회의에서 뉴질랜드 원조의 효과 측정 을 위한 모니터링 및 평가시스템이 채택되었음. $\mathrm{NZAID}$ 는 DAC의 개발원조평가원칙(Principles for the Evluation of Development Assistance) 을 근간으로 내부 평가를 강화하기 위해 평가 정책 과 가이드라인을 개발하고 있음.

ㅁ 동 평가 가이드라인은 다음의 요소들을 포함함.

- 프로그램 사이클과 평가의 통합, 사업수행시 고 려사항, 컨설턴트의 선정과 감독, 품질 관리, 보 고서 양식, 새로운 사항의 활용 및 배포, 평가에 있어서의 참여와 역량강화 등

ㅁ평가시 수원국의 참여를 정례화하고 있으나 타 공 여국과의 공동평가는 기관 내부의 역량부족으로 제한적인 실정임.

\section{2005년 DAC 동료평가 주요 결과}

ㅁ 원조정책 및 對국민 인식

- NZAID 설립 초기에 개발된 정책들이 의사결정 과정에 긍정적으로 반영되고 있으며 향후에도 합의된 새로운 정책 및 전략들이 지속적으로 시 행되어야 할 것임.

- 수원국이 보다 포괄적이고 지속적인 개발을 이 룰 수 있도록 적절하고 구체적인 국가별 제도 개 혁 및 정책 개혁 장려가 필요함.

- 지속적으로 對국민 홍보전략을 수립 - 시행하여 기관의 활동, 개발 이슈 및 성과에 관한 對국민 이해를 제고하여야 함.

ㅁ원조 규모 및 배분

- UN이 권고하고 있는 GNI 대비 ODA 비율을 $0.7 \%$ 로 확대하기 위해 뉴질랜드 정부는 현실적 이고 의욕적인 중기 계획을 수립하여야 함.

- 국제기구와의 활발한 협력을 위해 NZAID는 $\mathrm{ODA}$ 증액의 상당부분을 국제기구에 할애하여 다자간 개발기구에 대한 기여도와 발언권을 높 여야 함.

- 원조실적이 가장 뛰어난 태평양지역에 대한 현 행 지원 추세를 유지하고 아시아지역에서는 선 별된 소수의 국가에 양자원조를 집중시켜야 함.

ㅁ정책일관성

$-\mathrm{NZAID}$ 는 정책조언 권한을 가진 개발원조기관 으로서의 신뢰도를 기반으로 뉴질랜드 정부부처 전반에 걸쳐 개발정책일관성을 촉진시킬 수 있 는 위치에 있음. 이에 정부의 의제에 주도적 영 
향력을 발휘하고 분석 능력을 배가해야 함.

- 개발정책일관성 관련, 부처간 원활한 조정을 위 해 정부의 분명한 지침이 필요하며, 특정 정책분

야에 대한 목표와 정책일관성에 관한 정기 보고

를 통해 업무 범위를 규정할 수 있을 것임.

ㅁ 원조관리 및 실행

- 원조사업을 분야별 접근방식으로 추진하여야 함. 아울러 수원국과의 정책 대화 및 조정업무가
많아짐에 따라 현지사무소 파견 직원들의 수를 늘려야 하며 직원들의 수준과 능력을 향상시켜 야 할 것임.

- 국가 주도의 대규모 양자간 국별 프로그램을 보 완하기 위해 다양한 기금마련창구, 지역 프로그 램 육성, $\mathrm{NGO}$ 와 공동 기금마련 등을 검토하고 수혜국의 주인의식을 강화할 수 있도록 노력하 여야함.

〈NZAID 조직도〉

NZAID 청장

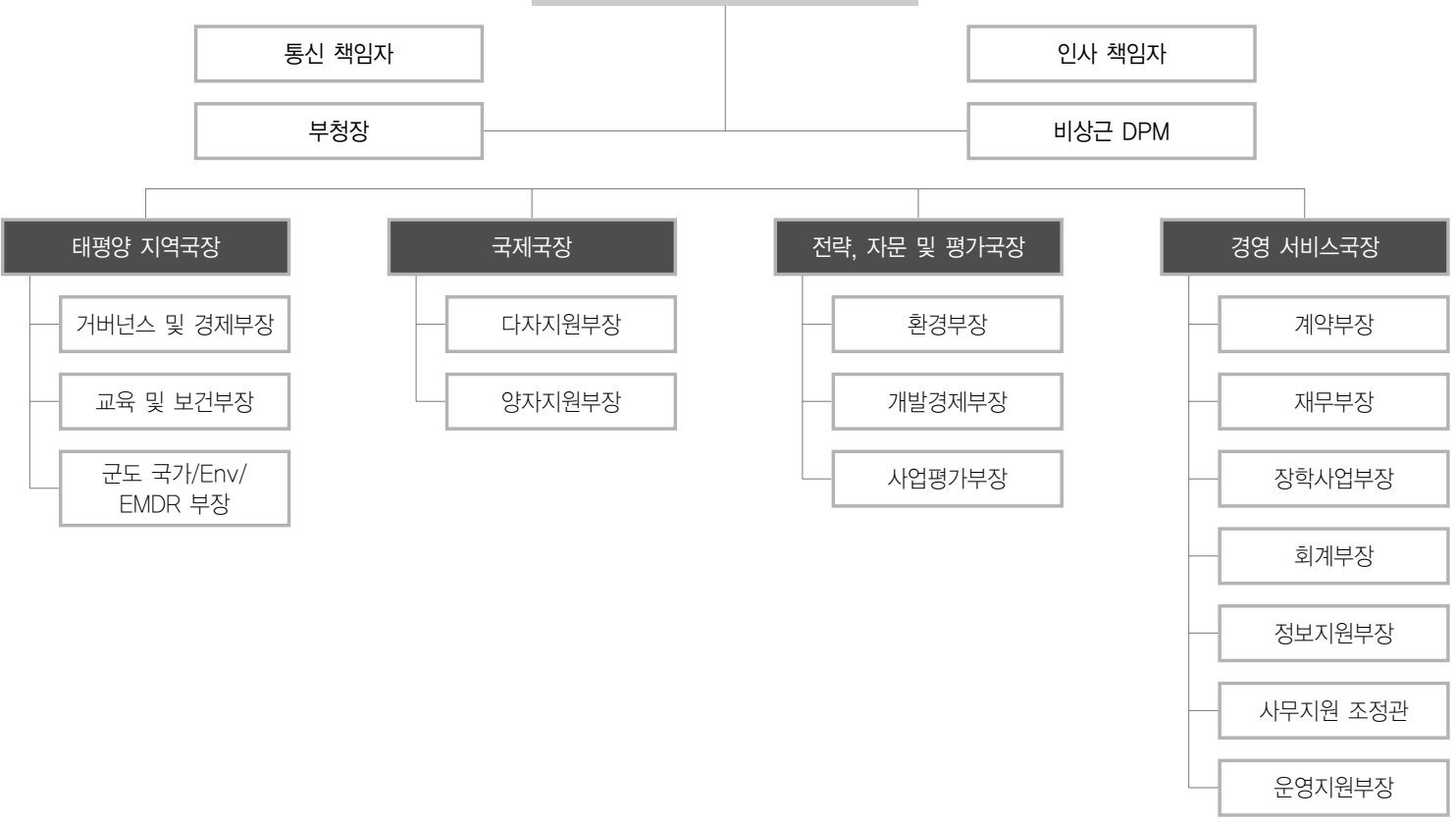

